\title{
A Self-Reinforcing Process on Sidewalk: A Case Study in Jatibaru Raya - Tanah Abang Sidewalk, Jakarta
}

\author{
Sulistya Indriani ${ }^{1}$, Rossa Turpuk Gabe ${ }^{2}$, Joko Adianto ${ }^{1}$ \\ ${ }^{1}$ Department of Architecture, Universitas Indonesia, Indonesia \\ ${ }^{2}$ Department of Architecture, Universitas Indonesia, Indonesia (corresponding author) \\ rossa@ui.ac.id
}

\begin{abstract}
The focus of this study is to analyze a sidewalk as a pedestrian path, not only as a means to reach or return from a destination, but also produce activities as a self-reinforcing process at a certain time. These activities are certainly triggered by the presence of various users and their perceptions based on the sidewalk context. The phenomenon can be seen along the sidewalk in Jalan Jatibaru Raya Tanah Abang, Jakarta, Indonesia. Its function as transit and the commercial area certainly influences the activities in the sidewalk. Thus, walking is not the only activity on the sidewalk. People do selling, buying, or waiting there. The methodology of this study is a detailed observation of the physical environment as the main factor of human gatherers. Then, pedestrians become the primary reference for other actors to come and do activities on the sidewalk of Jalan Jatibaru Raya, Tanah Abang, Jakarta, Indonesia. The observation is using ANT (Actor-Network Theory) as a basis for developing the phenomenon. The result showed that the process of a self-reinforcing process in the sidewalk happens when someone starts doing something, allowing a clear tendency for others to join, either participating or merely experience or see what others do. However, the interconnection between the actors is inseparable from activity, space, and time.
\end{abstract}

(c) 2018 IJBESR. All rights reserved.

Keywords: Self-Reinforcing Process, Sidewalk, Actor-Network Theory

\section{Introduction}

The main function of a sidewalk is a pedestrian path used for walking from and to some places with a significant impact on combining physical activity into everyday life [1,2]. Commonly, sidewalks are unassuming, standardized pieces of gray concrete placed between roadways and buildings [2]. A sidewalk is also used as a space for seeing, hearing, and speaking that cannot be separated from the physical existence of sidewalk and activities in it, which included integral parts of the street and urban life [2,3]. From the pedestrian perspective, the sidewalk is conceptualized as a space with four planes. The planes are ground planes, building a wall, canopy, and roadside. The ground plane is the closest area to the building or the edge (wall building) and most directly felt by pedestrians. It is connected directly to the roadside where vehicles are situated. The building wall and roadside consist of vertical elements that produce space as a sidewalk. The last plane is the canopy generated from some projected elements. These elements will affect the overall sidewalk, for example, climate and weather. Furthermore, the four planes will influence each other [1].

These four planes will affect the space experience of pedestrians. The effect will be seen from the activities that occur in tune due to sidewalk existence $[1,4,5]$. Based on its context, the sidewalk can be changed into a space that can support activities where the sidewalk is located. This phenomenon can be seen in Sidewalk of Jalan Jatibaru Raya, Tanah Abang, Jakarta, Indonesia, located in transit and commercial area. It is close to Tanah Abang Station, TransJakarta 'Tanah Abang Explorer' Terminal, and Tanah Abang 
Bus Terminal, and next to Informal Market, Jatibaru Market, and Block A to Block G Tanah Abang. The context can influence the presence of actors on the sidewalk and how the actors will interpret and utilize the sidewalk as a space for doing activities based on their perspectives. The different perceptions of each person will produce various activities. So the sidewalk on Jalan Jatibaru Raya is not only a space for pedestrians but a place where buying and selling transactions takes place, transition space (from and to), waiting's space for arriving passengers, and space to wait for public transport. Thus, according to Jacobs (1961) and Whyte (1988), the sidewalk as a vibrant open space can control undesirable people and activities [2]. Even though there are so many activities, but they still have causal relationships with each other. The causal effect will, in turn, trigger the occurrence of a self-reinforcing process.

According to Jan Gehl (1987), self reinforcing is a process when a person starts to do something that creates a clear tendency for others to join, either through direct involvement or experiences it or merely sees it [3]. This is suitable for the statement in the book "Science In Action: How To Follow Scientists and Engineers Through Society" that the presence of actors can influence other actors in doing something [6,7]. Jan Gehl (1987) says that there are two processes in life between buildings, namely positive and negative processes. The positive process is "something happens because something happens", while the negative process is "nothing happens because nothing happens". According to Jan Gehl (1987), the positive process happens when an activity becomes a source of inspiration and the other actors' reference to do activities. For example is when some children begin to play on the playground, they will inspire others to come out and join in the games, and this small group will quickly grow to start the process. Meanwhile, a process can be deemed as negative when someone does not want to leave the house and sit on the bench outside the house. This happens because nothing is interesting to see [3].

\section{The Aims of The Study}

Based on the context, the sidewalk as a pedestrian space can produce a selfreinforcing process in the form of activities. Therefore, this study focus on understanding how the activities can be connected at certain times on the sidewalk. Moreover, it will explore how these activities can be triggered by the presence of various users and their perceptions on the sidewalk context, then how the physical environment becomes the main factor in human gatherers. Thus, this study is aimed to explain how space can be formed by an interaction between actors, how these actors will affect and engage in activities such as causal relationships that are included in the self- reinforcing process. Furthermore, another aim of this study is to learn how these activities existed in terms of space, movement, and time. In order to analyze these activities, a social perspective is needed by using Latour's theory.

Latour's theory is a concept of ActorNetwork Theory (ANT). ANT states that social activity does not consist of human actors only but also non-humans. Together they produce a pedestrian area as a space for doing activities [8]. So they do not act alone. Their existence in space occurs because of the existence of others and will require to connect [6]. As a result of their presence and activities, the actors can change the function or define the space [8]. This happens based on the respective perceptions of space. Such space is the result of connectedness between human, human-non-human, and non-human connections [6].

Based on the ANT point of view, human and non-human are placed in the same position called generated symmetry. It means that humans and non-human are equal to each other with similar abilities. A human or nonhuman is an object that will become an actor when given social action. Thereafter, it can become an actant if there is an ability to 

p-issn: 2581-1347 | e-issn: 2580-2607 | Pg. 55 - 62

influence other actors that may come in and out as well as influence the system of a network [6].

The existed actors, groups, and actions can connect to make a network [6]. According to Latour (2005), connectivity through this network presents objects, entities, actors, and processes. Furthermore, society does not refer to the presence of the object, but the occurrence resulted from the relationship between human and non-human [7]. According to Latour (1987), ANT focuses on a process of actor continuously change, as an actor's action can affect other actor actions, and so on [3]. It can be seen from an actor movement from one point to another to the inter-network [7]. This happens because of the social changes that can be seen from associations, connections, and relationships that are not only a result of "social activity", but created and updated in a network without social change [6].

\section{Methods}

This study is conducted through a detailed observation of the physical environment (non-humans) as the main factor of human gatherers. Furthermore, pedestrians become the primary reference for other actors (humans) to come and do activities on sidewalk Jalan Jatibaru Raya, Tanah Abang. Thus, the observation is using ANT (ActorNetwork Theory) as a basis for developing the phenomenon. The case discussion uses a qualitative approach with an analytical descriptive writing method. The method of observation is conducted by using: (1) literature study, included social space in outdoor between buildings. The social space consists of the appearance of human and non-human actors. This existence has activities, and such activities become a secondary component to create space or act as a reference for other actors to come and do activities in outdoor public space. (2) Case study observation is conducted by experiencing the space directly in the early morning (05.30 a.m.) until evening (09.00 p.m.) during the weekdays and weekends (Monday to Sunday). The activities to be observed are those with causal connectivity based on space and time.
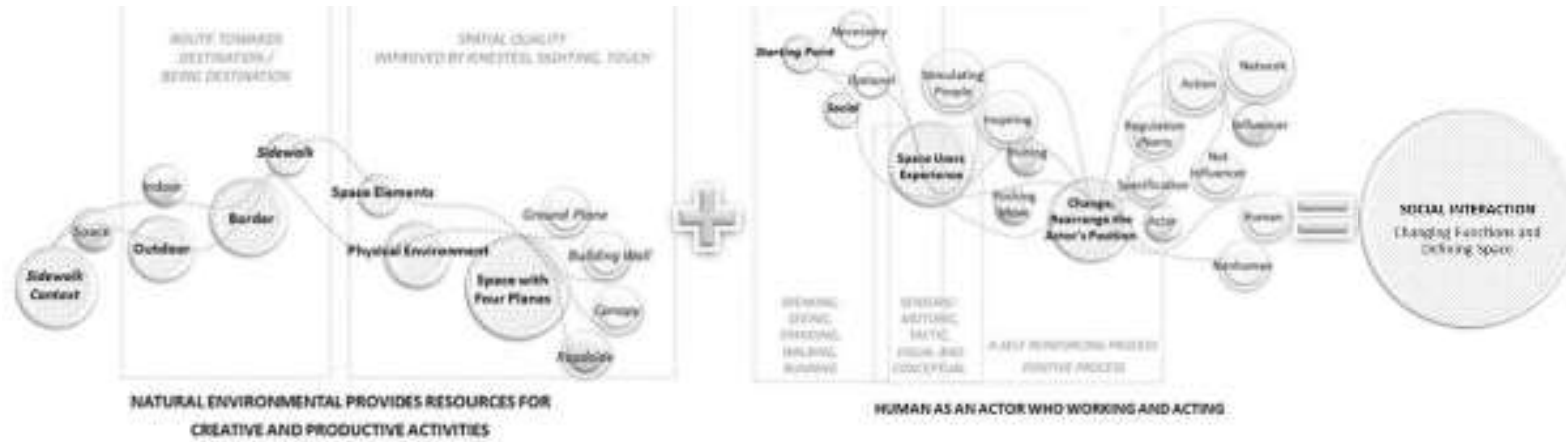

Figure 1: Sidewalk Case Study Synthesis. Source: Indriani, April 2018

Based on Figure 1, a diagram of a method used to observe the case study in Jalan Jatibaru Raya, Tanah Abang, the social interaction has resulted from human activities in the form of working and acting to make creative and productive activities by utilizing the nature as resources provider. It is triggered by the existence of nature (sidewalk and context) as a route or part of the destination. The presence of this sidewalk will then invite someone to move in it. This activity will be a starting point to stimulate, inspire, encourage people to do other activities. In return, it will cause a change or rearrangement of the actor's position in the sidewalk. 


\section{Results and Discussions}

The result of this observation conducted along Jalan Jatibaru Raya, Tanah Abang, Central Jakarta is a self-reinforcing process on the sidewalk. These were held from March to April 2018 on them who experience the sidewalk of Jalan Jatibaru Raya directly (thus, pedestrian perspective) as well as motor vehicle passengers (around the site). The observation's main objects are pedestrians on Sidewalk Jalan Jatibaru Raya and their activities. The activities that are being observed must have a causality connection between them. This connection will then trigger a self-reinforcing process.

\subsection{The Characteristic of Sidewalk on Jalan Jatibaru Raya, Tanah Abang}

The sidewalk of Jalan Jatibaru Raya, Tanah Abang, is located in transit and commercial area. This condition caused the existence of various sidewalk users, such as mass transit users, public transportation, sellers, and buyers. This condition leads to different perspectives in using the sidewalk. So the sidewalk in question is not exclusively used as an area to walk from and to the destination but also as a part of the destination itself. It because there are other activities being performed, namely selling and buying, it becomes such a place to rest for a moment also, and passengers are stepping in or out of public transportations here.

The physical characteristic of the sidewalk is a combination of concrete and block paving. The sidewalk has a width of about 4-6 m, and there is a fence as high as $2 \mathrm{~m}$ along the side. There are physical characters in the form of objects In and around the sidewalk. According to Bloomberg's theory, the physical characteristics on the Sidewalk of Jalan Jatibaru Raya, Tanah Abang can be defined as four planes, namely ground plane (the entrance to Tanah Abang Station, the front yard of the station, signage, ditch, power poles, roadblocks, trees, street furniture (bins, bench, stalls, street lights, signs)), building wall (station building walls, faces buildings, bridge columns, barriers, facade textures, setback), canopy (weather, climate, street light, landmark towers), and roadside (public car parks).

\subsection{Actors and The Formation of Networks on The Sidewalk}

Based on Latour's theory, the physical characters discussed above are non-human actors, while the pedestrians, sellers, buyers, and drivers of public transportation included as human actors. The non-human actors then serve as a trigger for the presence of human actors to come and move on the sidewalk; thus, their target is pedestrians. All human and non-human are objects on the sidewalk and can only be regarded as human and nonhuman actors when a social action has been given. For example, a flowerpot is an object on the sidewalk, and it will become an actor when the pedestrians sit on the flower pot.

Based on Bloomberg's theory, ground plane, canopy, roadside, and building side are nonhuman actors that will trigger the presence of human actors. For example, the existence of a sidewalk (non-human actor) tends to appeal to pedestrians as social actors to come, move, and do activities on the sidewalk. This way, the sidewalk becomes a part of the momentary destination. The momentary destination generally has vertical and horizontal elements and provides the ability and atmosphere to space [1]. For example, people sit leaning along the edges of building walls, columns, and plant pots made of concrete. This phenomenon is in line with the phrase "If the edge works, so does space" [3]. Through this example, we can find out that edge (building walls, columns, and plant pots) is a building side's object on the sidewalk. That object subsequently becomes a human actor when people sit leaning along the edges. These non-human actors will turn to actant if the existence of the building side (building wall, columns, and plant pots) can provide pedestrians and other actors a place to lean/sit on that make them coming and doing activities on it. 
The next example is the horizontal elements (canopy) in the form of trees and roofs of buildings that are projected perpendicularly to provide shade, which can trigger the human existence. People who choose to sit under a tree will be provided with the shade. So, the shade can be called an actant as it provides a place to sit/lean on the sidewalk to the users. Another example is the presence of traders on the sidewalk. It is not only about the frequency that pedestrians pass through this space but also how traders create the non-human actors. Traders who sell their goods near the fence can lean on it and even make use of the gaps of the fences as a place to display their goods such as tissues and socks. So, the fence as a nonhuman actor can be called an actant because of traders' existence on it.

Another example, the location chosen by the public transportation drivers to take and drop the passenger is also considered on the basis of the ground plane size, applicable regulation/ norms/ conditions such as the absence of guardrails and roadblocks. Their preference would be different compared to the options chosen by children who play on the sidewalk. It appears that they prefer the one with guardrails that can separate the sidewalk with roadside so that they can avoid the motor vehicle movement. As for Security and Traffic officers as well as the sweepers, their activities are equal to the pedestrians'.

\subsection{A Self-Reinforcing Process on Sidewalk}

Figure 2 generated from the synthesis of seven theories. The main theory of the generated system (equalizing between human and non-human factors and placing it within the same framework). The core of the diagram above explains that the sidewalk is a trigger for the presence of pedestrians to come and move in it. These pedestrians will be the main factor of a self-reinforcing process that will result in activities from the presence of static traders, drivers of public transportation, and dynamic traders. The presence of four actors will trigger the appearance of a Security Officer, Traffic officers, and sweepers.

Through this network (Figure 2), we can understand the order of human actors' presence. The order of attendance includes:

1. pedestrians stimulate bajaj, public transportation, motorcycle taxi drivers (public transport) and static traders to come;

2. the existence of public transport becomes the source of dynamic traders' reference and the Traffic officers to come, while the presence of static traders can turn pedestrians into buyers;

3. the existence of static and dynamic traders encourages the arrival of Security Officer;

4. the overall appearance of such actors potentially causes waste issues to promote the entry of sweepers. 


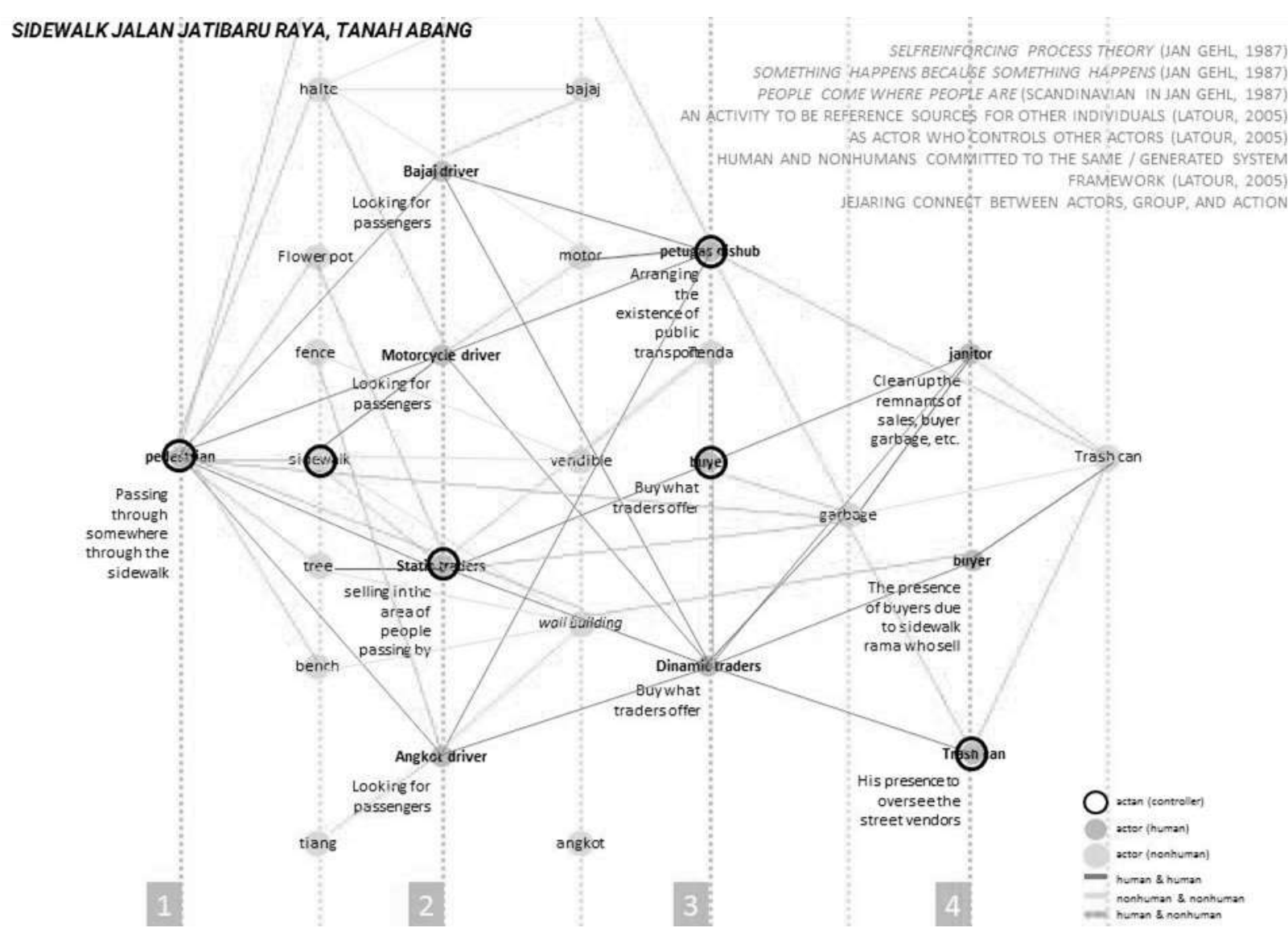

Figure 2: The Network of Actors, Group, Action on Sidewalk Jalan Jatibaru Raya, Tanah Abang. Source: Indriani, April 2018

In Figure 2, more lines on the point (human actors and non-human actors) indicate more connectedness with other actors. The more connectedness means greater potential that the actor becomes the actant (the controlling actor). In conclusion, actants in figure 2 included pedestrian, sidewalk, static trader, buyer, Traffic, and Security officer.

Pedestrians, as the main actors of a selfreinforcing process and actant (control actors), can come and go out of the network. The network's inbound capability makes it a role-changing actor. On the diagram notes that someone walking on the sidewalk constitutes a primary activity of pedestrians (figure 3). However, when the pedestrians take public transportation to their office, they will exit the sidewalk network and change the role of a pedestrian to become a worker. So pedestrians can transform their role into workers, settlers, and buyers. This change of role is possible as pedestrians have connections with other actors in and around the sidewalk to interact as well as control the presence of other actors.

\subsection{Time as a Performance Contributor to The Occurrence of A Self-Reinforcing Process}

In addition to actants, other factors that support the presence and absence of actors are time changes. This happens because time affects the performance of the actor (the elements of space/physical space). The performance of the actor also causes the role change of the actor's object (when given a social action) and becomes a role-changing actant (actors).

It can be seen during the morning and afternoon times that Tanah Abang Station Stop is quite crowded by the user, while in the afternoon, the seats at the bus stop are crowded by many traders. These time 
changes make a difference in the quality of the presence of space elements (non-human actors). That is because, during the noontime, the bus stop area becomes hot due to the fierce sunlight, so many people would not want to sit there despite the shades. In contrast to the afternoon time, the presence of the trees' and shelters' shades affect the right space to wait, rest for a while. The presence of people can be used by the traders to sell their goods, and therefore the traders adorn the sidewalk area in Tanah Abang Station area. It can be said that time is a performance contributor to non-human actors.

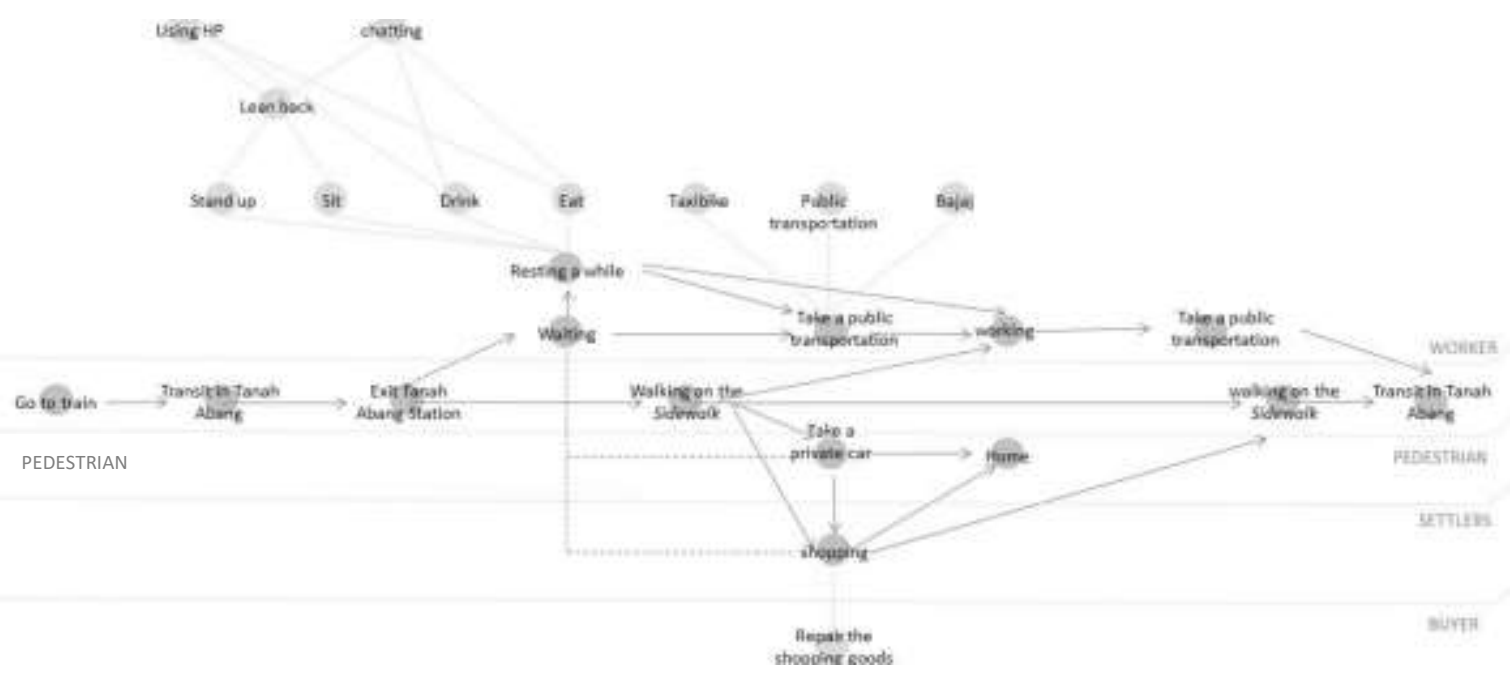

Figure 3: Connectivity Chart: Pedestrian as An Actant Based on Possibility Source: Indriani, April 2018

The next example that shows the time as performance contributor to the human actor can be seen from the activities conducted from morning to evening time that will drain energy from human actors. Human-owned energy becomes the performance of human actors' presence. So that the actors take a break at night time, this causes people to close their stores, or end the economic transaction and then go home. The actor's absence drives other actors to leave the sidewalk as well. This is in line with Gehl's theory, "something happens because something happens".

Other than its role as a contributor to nonhuman and human actor performance, time may drive the noncompliance with the applicable rules. This can be seen through the presence of pole signs - for example, the prohibition sign for parking the vehicles as well as selling carts in the sidewalk. In the morning until afternoon time, there would be no vehicles and sell carts parked on the sidewalk. However, during the night time, the sidewalk would be crowded by the carts. It certainly violates the applicable rules for the sidewalk. Yet it does not make the traders leave the sidewalk, especially during the absence of Security officers to patrol the area.

Based on the discussion above, Jalan Jatibaru Raya - Tanah Abang Sidewalk is known as one of the spaces which have a selfreinforcing process. It can be seen from the presence of the physical environment (nonhuman actors) that trigger the presence of pedestrians (human actors). The presence and activities of pedestrians will encourage other actors to come and move around the sidewalk as well as soon. So that activities with one another still have a causal effect. The activities that occur are influenced by where the sidewalk is located and time.

\section{Conclusion}

The initial designation of a sidewalk is a path to walk from and to some destinations. 
However, the sidewalk role is currently changed to become part of the destination. This phenomenon can be seen on the Jalan Jatibaru Raya sidewalk, Tanah Abang. The change is inseparable from the sidewalk location. Its presence in the transit and commercial areas led to the presence of various actors. Various perceptions of the actors on the sidewalk can alter its function and define the space. This results from the connectedness through social interaction between human-human, human-non-human, and non-human-non-human.

Sidewalk has a non-human actor as a major factor for gathering humans to move around in it. The activity is a way how man process other actors. Those activities can be inline or not with the sidewalk function. However, these activities have a cause and effect relationship to each other.

The activities involved in causing the causal relationship are included in a self-reinforcing process. The process occurs when a person starts doing something, and there is a clear tendency for others to join in, either by participating in it or just experiencing or seeing what others do. It will form a connectedness, both socially and spiritually, to make Jalan Jatibaru Raya as a space for social interaction. In this case, pedestrians as human actors become the primary reference for other actors to come and move on Jalan Jatibaru Raya sidewalk, Tanah Abang. Therefore, pedestrians are the primary trigger of the process and categorized accordingly as actants (controlling actors).

The perceptions diversity generated by actors produces different activities and yet interconnected with others, resulting in subjective and objective time in space. Time is something that does not depend on the actor and his activity. It is a factor that affects the presence and absence of actors. This is proven during the observation that time is present as a contributor to non-human and human actors' performance. Time also present, as well as their noncompliance with the regulations apply in the sidewalk.

\section{References}

[1] Bloomberg, M. R. Active Design: Shaping The Sidewalk Experience. New York City; 2013.

[2] Lokaitou, A. Conflict and Negotiation over Public Space. Cambrige, Massachusets: The M.I.T. Press; 2009.

[3] Gehl, J. Life between Building: Using Public Space. New York, United States of America; 1987.

[4]Tuan, Y.-F. Place: An Experiental Perspective. Dalam Y.-F. Tuan, Space and Place. American Geographical Society; 1975. p 151-165.

[5] Tuan, Y. F. (n.d.). Space and Place: The Perspective of Experience. London: University of Minnesota Press.

[6] Latour, B. Reassembling The Social: An Introduction to Actor-Network-Theory. New York: Oxford University Press; 2005.

[7] Libratono. Preferensi dan Formasi Spasial Pedagang Kaki Lima (Studi Kasus: Pasar Baru Bekasi). Depok: Fakultas Teknik, Universitas Indonesia; 2013.

[8] Lefebvre, H. The Production of Space. Cambrige: The M.I.T. Press; 1991.

[9] Jacobs, A. B. Great Streets. Cambrige, Massachusets: The M.I.T. Press; 1974.

[10] Lynch, K. The Image of City. Cambrige: The M.I.T. Press; 1960. 